\title{
Optimization of Electrolytic Cleaning of Low Carbon Steels
}

\author{
S. Urréjola ${ }^{1}$, J. Lora and R. Devesa-Rey
}

\begin{abstract}
Electrolysis is an effective method for recovering rusted pieces in acceptable times of operation without generating practically any residues and with a very low cost. The process is controlled by the concentration of electrolyte used, the current intensity selected and the operation time, among others. Knowing the best operating conditions allow cleaning the rusted parts more efficiently. In this work, it was carried out an optimization of the cleaning process by means of an incomplete 33 factorial design. The substrate selected consists of several low steel carbon probes $(\mathrm{Fe}>99.7 \%)$, which were subjected to oxidation in the laboratory to ensure homogeneity. The independent variables assayed included the concentration of the electrolyte employed (x1), the current intensity (x2) and the temperature of operation (x3), whereas the dependent variable was based on the weight differences of the probes after being subjected to the cleaning process. The results obtained showed that the optimal conditions for removing rust from low steel carbon were $5 \%$ of electrolyte, a current intensity of $3 \mathrm{~A}$ and a temperature of operation of $40{ }^{\circ} \mathrm{C}$. These results demonstrated the potential application of electrolytic cleaning combined to an optimization by means of a factorial design to restore low steel carbon pieces.
\end{abstract}

Keywords: Oxidation; electrolytic; metal; cleaning; factorial design

\section{Introduction}

The electrolytic cleaning is a process commonly used in the steel industry for removing contaminants adhered to metal surfaces. This process takes place in two stages: in the first, called cleaning step, the steel is subjected to a series of pre-treatments such as dipping in alkaline solution and brushing or blasting in order to remove grease, oil and particles more weakly attached. In the second, metal surface is submitted to electrolysis by dipping it into a conducting solution and connected to an external power source.

Cleaning can be performed in cathodic or anodic current (Zujur and Rosales, 2012). Under cathodic current, the metal receives a negative charge and hydrogen gas is produced in the metal surface. Under anodic current, the metal receives a positive charge and oxygen gas is produced in the metal surface. This gas bubbling promotes the release of the metal oxides from the surface of the steels.

Electrolytic cleaning can be used for removing the adhered oxides on the metal surfaces due to corrosion processes. Oxidized piece can be placed in the cathode of the cell, and then oxygen release is observed after application of a given current density. Hydrogen, when released, promotes the detachment of the adhered oxides particle by particle (Mantell, 1980). Sometimes, when the piece to be cleaned is extremely delicate, the piece can be submitted to alternate cycles of cathodic and anodic cleaning deliberately, to produce a slow release of the adhered oxides. This effect was applied in cleaning daguerreotypes of the nineteenth century (Da Silva et al., 2010), alternating basic (1\%

${ }^{1}$ Defence University Centre, Naval Academy, University of Vigo. Plaza de España, s/n, Marín. 36920.

Spain.

*Corresponding author. 
$\mathrm{w} / \mathrm{v}$ sodium metaborate) and acid electrolytes $(0.3 \% \mathrm{w} / \mathrm{v}$ citric acid $)$ with current intensity variations and placing the daguerreotype alternatively as anode and cathode.

Sometimes electrolytic cleaning produces an irregular cleaning, which mainly affects the so-called "high points", i.e., the most outstanding oxide layers within the topography of the steel probe. In the "low points", however, where there is no corrosion or this is insignificant, the pickling process produces an oxidation of the original metal, producing a passivation layer. The result of both processes is an electrolytic polishing; where prominent parts of the roughened surface are reduced and low roughness slightly increase by passivation. The effect is a regularization or continuity of the surface (Mantell, 1980).

Other authors have highlighted the advantages of electrolytic cleaning against different methods. Chaves and Jeffrey (2015) studied the removal of oxides by different techniques, analysing the mass loss, the resulting surface topography, the pit depth and localized corrosion of steel probes after being exposed to corrosion in marine environments of high salinity. These authors found that chemical cleaning is useful for removing recent corrosion, although the effect of the cleaning agent generates the appearance of new oxides, acting itself as a corrosive agent. Exposure to these cleaning agents also produced pitting corrosion of the steel probe. Ultrasonic cleaning did not produce new corrosion products; although their effectiveness was higher in mild to moderate oxidations. Electrolytic cleaning, according to Chaves and Jeffrey (2015) proved to be effective in removing oxides without causing new corrosion products, although it was moderately slow process.

Removal of corrosion is a key step for recovering the oxidized steel probes and the application of new coatings that will serve as protective layer of the clean surface. The electrolytic cleaning is employed as a method for removing impurities, oxides, and small cracks, which can significantly reduce the adhesion of new coatings (Cheng et al., 2010). The electrolytic cleaning is an environmentally friendly method, which results effective also for large pieces with a simple and flexible methodology. However, there are two major problems that can arise from electrolytic treatments: on the one hand, the application of repeated cycles over time can cause a decrease in mechanical properties and on the other hand, the formation of hydrogen which can be incorporated to the material causing fragility of the piece (Cheng et al., 2010). Therefore, the electrolytic cleaning can produce unequal effects when cleaning the steel probe, which must be controlled to cleaning efficiency (Kumruoglu and Özel, 2014). According to these authors, optimizing cleaning under different current intensities and temperatures, aspects that have been studied in this work, and including the effect of electrolyte.

In this work, current intensity, temperature and the concentration of the electrolyte were optimized in order to produce the best cleaning in steel probes, which was evaluated through weight differences. The results obtained will serve to reduce time and cost of the process, as well to maximise the detachment of the oxides adhered to surfaces.

\section{Materials and Methods}

\section{Steel probes}

This study was carried out by placing the metal probe as the anode of the cell. Probes selected were steels with low carbon content $(0.040 \%)$ and $0.21 \%$ of other 
alloying elements. The dimensions of the pieces are $0,8 \times 75 \times 153 \mathrm{~mm}$ and their chemical composition is reflected in Table 1:

Table 1. Chemical composition of the Steel probes employed in this study

\section{Probe composition (\%)}

\begin{tabular}{|l|l|l|l|l|l|l|}
\hline $\mathbf{C}$ & $\mathbf{P}$ & $\mathbf{S}$ & $\mathbf{M n}$ & $\mathbf{S i}$ & $\mathbf{A l}$ & $\mathbf{F e}$ \\
\hline 0.040 & 0.006 & 0.006 & 0.16 & 0.010 & 0.026 & $>99.7$ \\
\hline
\end{tabular}

The macro- and microscopic appearance of the probes, before and after corrosion can be seen in Figure 1.

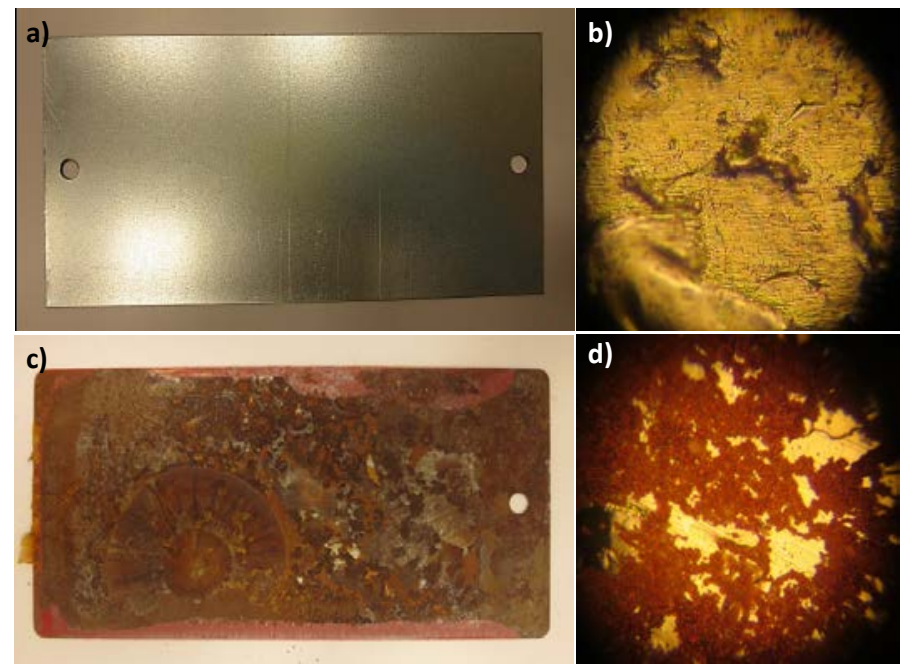

Figure 1. Probes employed in this study: a) macroscopic view before corrosion; b) microscopic (40X) view before corrosion; c) macroscopic view after corrosion; and d) microscopic (40X) view after corrosion

\section{Electrolytic cleaning procedure}

The electrolytic cleaning was carried out by placing steel probe as the anode of the cell and a graphite sheet as the cathode. Both electrodes were immersed in an electrolytic solution of $\mathrm{NaOH}$, with variable composition according to the optimization process design, and connected to a power source with variable current intensity, selected for each experiment according to the optimization design.

The three variables, which were optimized to produce the best cleaning results, were the concentration of the electrolyte, the current intensity and temperature. For each variable three levels were tested: minimum and maximum values, and an intermediate experiment.

- Concentration of the electrolyte: $\mathrm{NaOH}$ concentration varied from a minimum value of $2.5 \%(\mathrm{w} / \mathrm{v})$, to an intermediate value of $5 \%(\mathrm{w} / \mathrm{v})$, and finally analyzing a maximum 
value of $7.5 \%(\mathrm{w} / \mathrm{v})$. Previous experiments carried out at $1 \%(\mathrm{w} / \mathrm{v})$ showed good cleaning results but long times of operation so therefore concentration was increased to decrease the total time of the experiment. Higher concentrations of $7.5 \%(\mathrm{w} / \mathrm{v})$ were also tested but they damaged the steel probes.

- Current intensity: maximum current intensity was placed at 3 Amperes. Minimum and intermediate values were fixed at 2 and 2.5 Amperes, respectively.

- Temperature: temperature varied from a minimum value at room temperature $\left(20^{\circ} \mathrm{C}\right)$ through an intermediate value of $30^{\circ} \mathrm{C}$, and up to a maximum value of $40^{\circ} \mathrm{C}$.

The steel probes were allowed to stand in the electrolytic solutions up to 10 minutes and after that weight losses and factorial design was analyzed.

\section{Experimental design: Box-Behnken optimization}

The response surface methodology consists of a group of mathematical and statistical techniques based on fitting empirical models to the experimental data obtained in relation to experimental design (Bezerra et al., 2008). Box-Behnken designs are a class of rotatable or nearly rotatable second-order designs based on three-level, incomplete factorial designs (Box and Behnken, 1960). The number of experiments $(\mathrm{N})$ required for full Box-Behnken design are given by the formula $\mathrm{N}=2 \mathrm{k}(\mathrm{k}-1)+\mathrm{C}_{0}$, where $\mathrm{k}$ is the number of factors and $C_{0}$ is the number of central points (Ferreira et al., 2007). The simplest equation describing a linear function is described by equation 1.

$$
y=\beta_{0} \sum_{i=1}^{k} \beta_{i} x_{i}+\varepsilon \quad \text { eq. (1) }
$$

where $\beta_{0}$ is the constant factor; $\beta_{i}$ represents the coefficients of the linear parameters; $k$ is the number of variables; $x_{i}$ represents the variables, and $\varepsilon$ is the residual factor associated with the experiments. When the experimental data do not fit a linear equation, then it is desirable to include levels in the input variables. In this case, a polynomial response surface must be generated. Box-Behnken experimental designs were constructed for situations in which it is desirable to fit a second-order model (equation 2).

$$
y=\beta_{0} \sum_{i=1}^{k} \beta_{i} x_{i}+\sum_{i=1}^{k} \sum_{j \geq i}^{k} \beta_{i j} x_{i} x_{j}+\varepsilon \quad \text { eq. (2) }
$$

where $\beta_{i j}$ represents the coefficients of the interaction parameters. These designs include a central point used to determine the curvature, and critical or optimal conditions are deduced from the above second-order function by including quadratic terms (equation $3)$.

$$
y=\beta_{0} \sum_{i=1}^{k} \beta_{i} x_{i}+\sum_{i=1}^{k} \beta_{i i} x_{i}^{2}+\sum_{i=1}^{k} \sum_{j>i}^{k} \beta_{i j} x_{i} x_{j}+\varepsilon \quad \text { eq. (3) }
$$

where $\beta_{i i}$ represents the coefficients of the quadratic parameters. Thus, the experimental data enable the development of empirical models that describe the interrelationship between operational and experimental variables by equations including linear, interaction and quadratic terms. 
The range of independent and dependent variables studied, as well as their coded values, are included in Table 2. The standardized (coded) dimensionless independent variables used, with variation limits $(-1,1)$, were defined as $\mathrm{x}_{1}\left(\mathrm{NaOH}\right.$ concentration), $\mathrm{x}_{2}$ (current intensity) and $\mathrm{x}_{3}$ (temperature).

Thus, the quadratic function obtained for all three variables is described in equation 4.

$$
y=\beta_{0}+\beta_{1} x_{1}+\beta_{2} x_{2}+\beta_{3} x_{3}+\beta_{12} x_{1} x_{2}+\beta_{13} x_{1} x_{3}+\beta_{23} x_{2} x_{3}+\beta_{11} x_{1}^{2}+\beta_{22} x_{2}^{2}+\beta_{33} x_{3}^{2} \quad \text { eq. (4) }
$$

where $y$ is the dependent variable, $\beta$ denotes the regression coefficients (calculated from experimental data by multiple regressions using the least-squares method) and $x$ denotes the independent variables. The experimental data were analysed by the Response Surface method with Statistica 7.0 software.

Table 2. Independent and dependent variables used in the study.

\begin{tabular}{llll}
\hline a) Independent variables & & & \\
\hline Variable & Nomenclature & Units & Variation range \\
NaOH concentration & {$[\mathrm{NaOH}]$} & $\%(\mathrm{w} / \mathrm{v})$ & $2,5-7,5$ \\
Current intensity & {$[\mathrm{T}]$} & Amperes & $2-3$ \\
Temperature & {$[\mathrm{T}]$} & ${ }^{\circ} \mathrm{C}$ & $20-40$ \\
\hline b) Coded variables, dimensionless & & & \\
\hline Variable & Nomenclature & Units & Variation range \\
NaOH concentration & $\mathrm{x}_{1}$ & $([\mathrm{NaOH}]-7,5) / 5$ & $(-1,1)$ \\
Current intensity & $\mathrm{x}_{2}$ & $([\mathrm{]}]-3) / 2$ & $(-1,1)$ \\
Temperature & $\mathrm{x}_{3}$ & $([\mathrm{~T}]-40) / 20$ & $(-1,1)$ \\
\hline c) Dependent variable & & & \\
\hline Variable & Nomenclature & Units & \\
Weight loss & $\mathrm{y} 1$ & $\mathrm{mg}$ & \\
\hline
\end{tabular}

\section{Results and Discussion}

The experimental test conditions (expressed as coded variables) and the experimental data obtained for the dependent variable $\mathrm{y}_{1}$ are shown in Table 3 . The relationship between coded and uncoded variables was established by linear equations deduced from their respective variation limits, according to equation 7 (Bezerra et al., 2008):

$x_{i}=\left(\frac{z-Z_{i}}{\Delta z_{i}}\right) \beta_{d} \quad$ eq(5)

where $\Delta z_{i}$ is the distance between the real value in the central point and the real value in the superior or inferior level of a variable; $\beta_{d}$ is the major coded limit value in the matrix for each variable, and $z^{0}$ is the real value in the central point. Coded variables were then assigned values of $-1,0$ and +1 , corresponding to the lowest, central and maximum limits of variation for each variable. The response surface obtained from the coded variables is therefore not influenced by the magnitude of each variable, which allows combination of the factors on a dimensionless scale. 
Table 3. Summary of the experiments carried out and the weight loss obtained.

\begin{tabular}{|c|c|c|c|c|}
\hline & \multicolumn{3}{|c|}{ Independent variables } & \multirow{2}{*}{$\begin{array}{l}\text { Dependent variable } \\
\text { Weight loss }\end{array}$} \\
\hline $\begin{array}{l}\text { Steel } \\
\text { probes }\end{array}$ & $\begin{array}{l}\mathrm{NaOH} \\
\text { concentration }\end{array}$ & $\begin{array}{l}\text { Current } \\
\text { intensity }\end{array}$ & Temperature & \\
\hline 1 & 0 & -1 & -1 & 0.01 \\
\hline 2 & 0 & 1 & -1 & 0.01 \\
\hline 3 & 0 & -1 & 1 & 0.42 \\
\hline 4 & 0 & 1 & 1 & 0.46 \\
\hline 5 & -1 & -1 & 0 & 0.01 \\
\hline 6 & -1 & 1 & 0 & 0.01 \\
\hline 7 & 1 & -1 & 0 & 0.01 \\
\hline 8 & 1 & 1 & 0 & 0.01 \\
\hline 9 & -1 & 0 & -1 & 0.02 \\
\hline 10 & -1 & 0 & 1 & 0.04 \\
\hline 11 & 1 & 0 & -1 & 0.02 \\
\hline 12 & 1 & 0 & 1 & 0.02 \\
\hline 13 & 0 & 0 & 0 & 0.01 \\
\hline 14 & 0 & 0 & 0 & 0.01 \\
\hline 15 & 0 & 0 & 0 & 0.01 \\
\hline
\end{tabular}

To ensure the quality of the analyses performed, Figure 2 shows the variation in observed vs predicted values for variables $\mathrm{y}_{1}$ to $\mathrm{y}_{3}$; good agreement between experimental and theoretical data was observed.

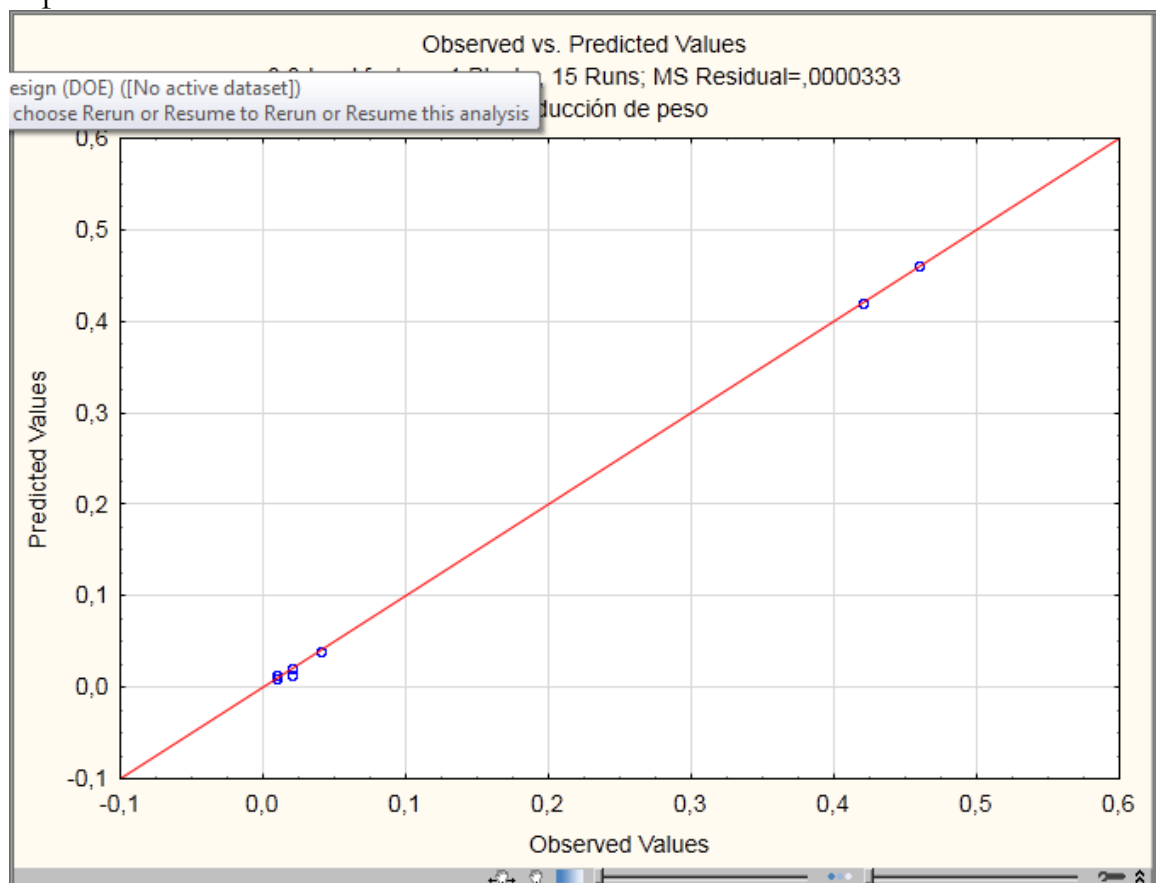

Figure 3. Predicted vs observed results in relation to the weight loss 
The Pareto chart of standardized effects of variable $\mathrm{y}_{1}$ is shown in Figure 4. In this figure it is clear that all variables tested have a great influence on the cleaning process: $\mathrm{NaOH}$ concentration, temperature and current, although the most influential factor was the quadratic combination of the concentration of $\mathrm{NaOH}$ with temperature. The current intensity and the concentration of $\mathrm{NaOH}$ have little influence as a linear combination and only become important in their synergistic effects with other variables.

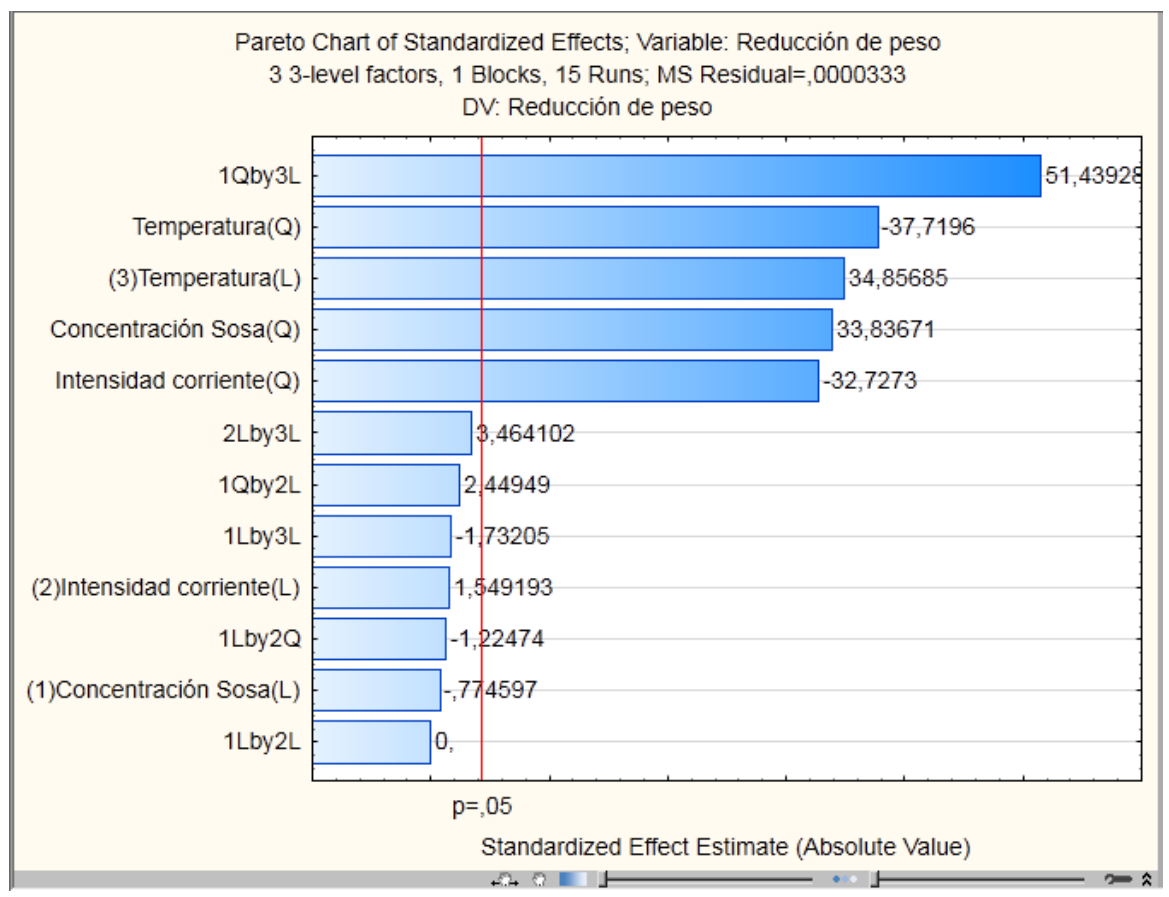

Figure 4. Pareto chart shows the most influential variables in the weight loss of Steel probes.

Figure 5 shows the variation in $\mathrm{y}_{1}$ with the most influential independent variables $\mathrm{x}_{1}$ and $\mathrm{x}_{2}$ (i.e. $\mathrm{NaOH}$ concentration and current intensity), within the ranges tested. The highest current intensity ( 3 Amperes) combined with intermediate $\mathrm{NaOH}$ concentrations resulted in the highest cleaning. 


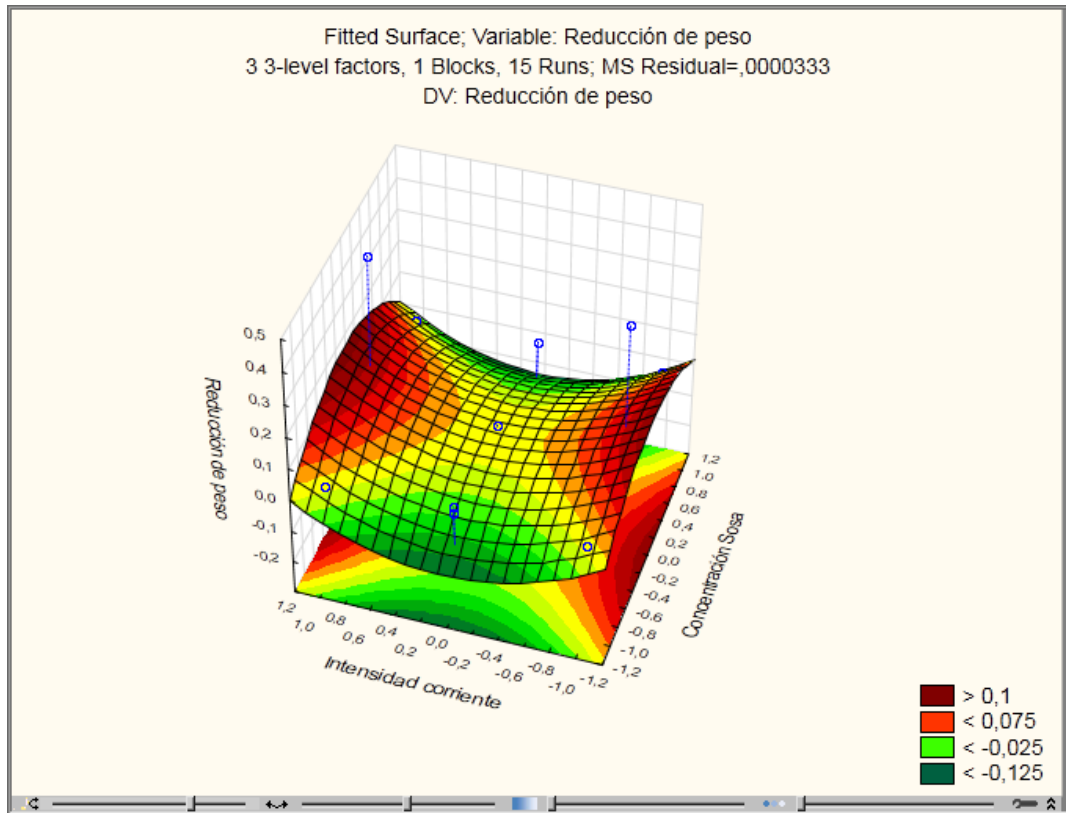

Figure 5. 3D-

graph showing

variations of

$\mathrm{NaOH}$

concentration with

current intensity,

and temperatura

fixed at an

intermediate value.

Moreover, Figure 6 shows the variation in weight loss values with $\mathrm{NaOH}$ concentration and temperature, with current intensity fixed at an intermediate value $\left(\mathrm{x}_{2}=2.5\right)$. In this case, the highest weight loss occurred at the maximum values of temperature while $\mathrm{NaOH}$ concentrations can be fixed at its medium concentrations. Weight loss in steel probes cleaning is four times higher when combining these conditions than those explained in figure $\mathbf{5}$.

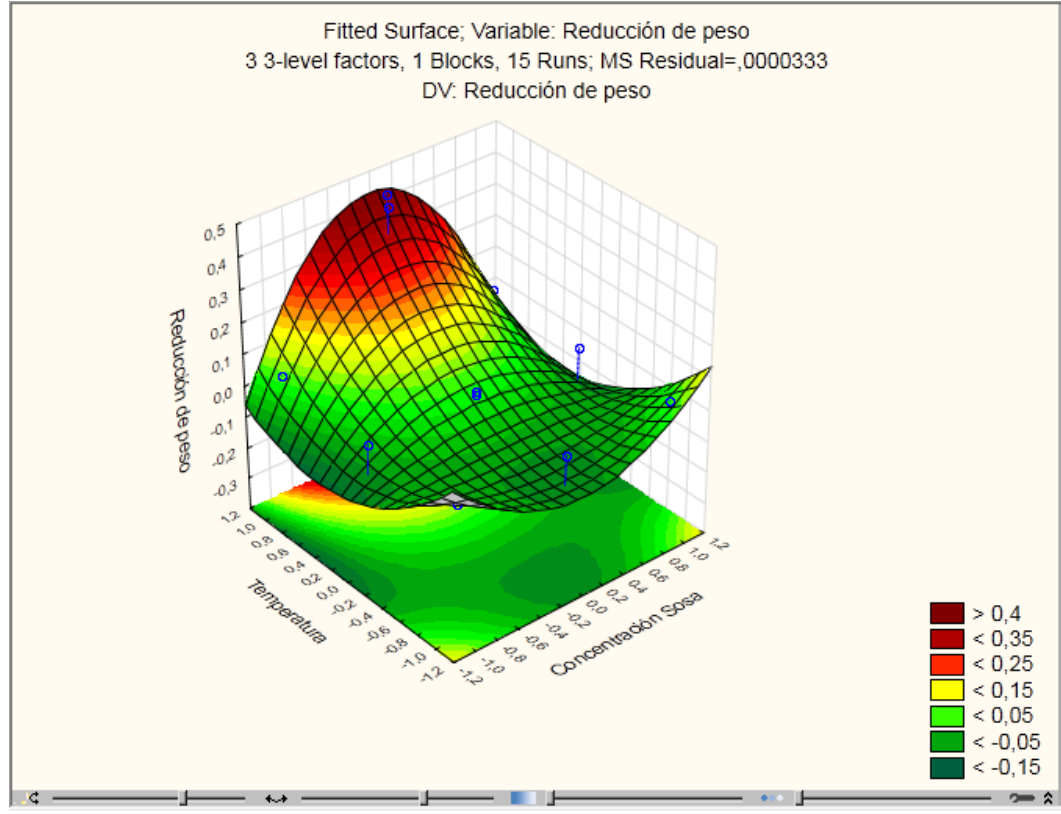

Figure 6. 3Dgraph showing variations of $\mathrm{NaOH}$ concentration with temperature, and current intensity fixed at an intermediate value. 
The highest weight loss was observed when combining the highest temperature with the highest current intensity, with the $\mathrm{NaOH}$ concentration fixed at its intermediate concentration.

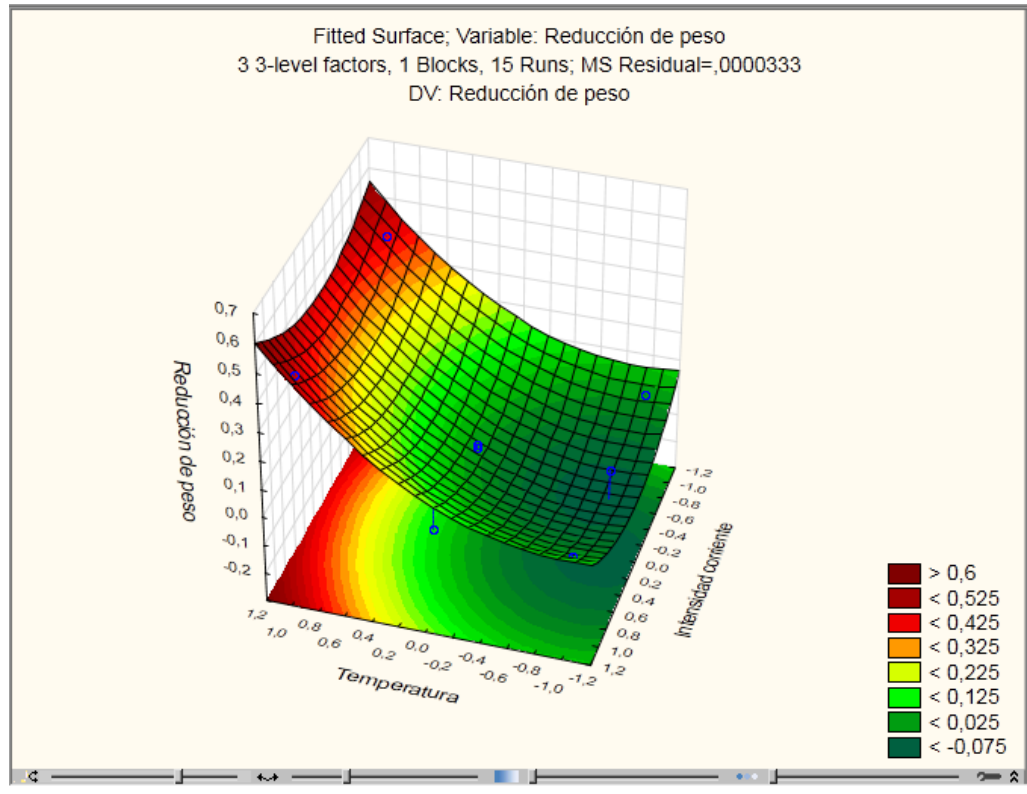

Figure 7. 3D-graph showing variations of current intensity with temperature, and $\mathrm{NaOH}$ concentrations fixed at an intermediate value.

\section{Conclusions}

In conclusion, the variable that most affected the weight loss in steel probes affected by corrosion is the temperature, which highly affected the experiments carried out. The highest temperature $\left(40^{\circ} \mathrm{C}\right)$ analysed significantly increased the weight loss in the steel probes. Additional experiments carried out probed that temperature higher than $40{ }^{\circ} \mathrm{C}$ can damage the steel probes so additional experiments are recommended to evaluate efficiency at higher temperatures. $\mathrm{NaOH}$ concentration probed to be a significant variable in the weight loss, and satisfactory results were obtained when using intermediate $\mathrm{NaOH}$ concentrations $(5 \%, \mathrm{w} / \mathrm{v})$. Thus, according to the factorial design carried out, the optimum condicitons may be achieved when combining $\mathrm{NaOH}$ concentrations at 5\% (w/v), 3 Amperes of current intensity and temperatures of $40{ }^{\mathrm{a}} \mathrm{C}$.

\section{References}

Bezerra M.A.; Santelli R.E.; Oliveira E.P.; Villar L.S., Escaleira L.A. (2008). Response surface methodology (RSM) as a tool for optimization in analytical chemistry. Talanta, 76: 965-977.

Box G.E.P.; Behnken D.W (1960). Simplex-sum designs - A class of 2nd order rotatable designs derivable of those of 1 st order. Ann. Math. Stat., 31(4): 838-864.

Chaves, I., Jeffrey, R., Melchers, R. (2010). Technical Note: Rust Removal from Steel Coupons after ShortTerm Marine Immersion. Corrosion, 71(7).

Cheng, Y., Gupta, P., Meletis, E. (2010). Surface characteristics of 4340 steel treates by electrolytic plasma processing. J. Mater. Sci, 45: 562-565. 
Da Silva, E., Robinson, M., Evans, C., Pejovic, A. (2010). Monitoring the photographic process, degradation and restoration of 21 st century Daguerreotypes by wavelength-dispersive X-ray fluorescence spectrometry. J. Anal. Atom. Spectrom., 25(5): 654-661.

Ferreira S.L.C.; Bruns R.E.; Ferreira H.S.; Matos G.D.; David J.M.; Brandão G.C.; da Silva E.G.P.; Portugal L.A.; dos Reis P.S.; Souza A.S.; dos Santos W.N.L. (2007). Box-Behnken design: An alternative for the optimization of analytical methods. Anal. Chim. Acta, 597(2): 179-186.

Kumruoglu, L., Özel, A. (2014). Electrolytic plasma surface cleaning of industrial metallic compounds. Acta Physica Polonica, 125(2): 379-381.

Mantell, C. (1980). Ingeniería electroquímica, ISBN: 84-291-7940-2.: Reverté.

Zujur, D., Rosales, A. (2012). Corrosión por corrientes parásitas de un tanque de limpieza electrolítica. Rev. LatinAm. Metal. Mat., S4: 24-28. 